Original Research Paper

\title{
GAMBARAN STRES KERJA PADA PERAWAT WANITA DI RS. X PALEMBANG
}

\section{Karina, Hilda Zulkifli, Novrikasari}

\section{Universitas Sriwijaya}

\section{Email Corresponding: \\ ain.karina@gmail.com}

Page : $7-14$

\section{Kata Kunci :}

Stres Kerja,

Perawat Wanita

\section{Keywords:}

Occupational Stress,
Female Nurses

\begin{abstract}
ABSTRAK
Sektor kesehatan berisiko menimbulkan stres kerja tak terkecuali pada perawat wanita. Penelitian ini bertujuan untuk mengetahui angka stres kerja berdasarkan sumber stres kerja pada perawat wanita di RS. X Palembang. Penelitian ini merupakan penelitian deskriptif dengan pendekatan cross-sectional dengan sampel sebanyak 54 orang perawat wanita di RS. X Palembang. Data diambil menggunakan Expanded Nursing Stress Scale (ENSS) versi Bahasa Indonesia. Responden dengan nilai di atas rerata sebanyak 21 orang $(38,9 \%)$ untuk skor total, Subskala Kematian dan Sekarat sebanyak 28 orang (51,9\%), Subskala Konflik dengan Dokter sebanyak 24 orang (44,4\%), Subskala Tidak Cukup Persiapan sebanyak 32 orang $(59,3 \%)$, Subskala Permasalahan dengan Teman Kerja sebanyak 23 orang $(42,6 \%)$, Subskala Permasalahan dengan Supervisor/Atasan 22 orang (40,7\%), Subskala Ketidakjelasan Pengobatan dengan responden sebanyak 22 orang $(40,7 \%)$, Subskala Permasalahan dengan Pasien sebanyak 29 orang (53,7\%), dan Subskala Beban Kerja sebanyak 24 orang $(44,4 \%)$. Uji Chi-Square yang dilakukan mendapatkan p-value yang berbeda pada setiap variabel yaitu, usia $(p$-value $=0,445)$, status gizi $(p$-value $=0,802)$, masa kerja ( $p$-value $=0,025)$, kebiasaan olahraga $(p$-value $=0,268)$, dan tingkat pendidikan $(p$-value $=0,076)$. Terdapat perbedaan yang bermakna pada stres kerja dengan masa kerja dan Subskala Tidak Cukup Persiapan merupakan sumber stres kerja dengan angka tertinggi.
\end{abstract}

\section{Published by:}

Tadulako University,

Managed by Faculty of Medicine.

Email: healthytadulako@gmail.com

Phone (WA): +6285242303103

\section{Address:}

Jalan Soekarno Hatta Km. 9. City of

Palu, Central Sulawesi, Indonesia

\section{ABSTRACT}

The healthcare is risky to cause occupational stress, including among female nurses. This study aims to determine the prevalence of occupational stress based on the source of occupational stress on female nurses at the RS. X Palembang. This research is a descriptive study with cross-sectional approach with 54 female nurses as respondents at RS. X Palembang. Data were collected using the Indonesian version of the Expanded Nursing Stress Scale (ENSS). Respondents with the scores above the average were 21 people (38.9\%) for the total score, for the subscales such as, Death and Dying were 28 people (51,9\%), Conflict with Physicians were 24 people (44,4\%), Inadequate Preparation were 32 people (59,3\%), Problems with Peers were 23 people (42.6\%), Problems with Supervisors were 22 people (40.7\%), Uncertainty Concerning Treatment were 22 people (40.7\%), Patients and Their Families were 29 people (53.7\%), and Workload were 24 people (44.4\%). The Chi-Square test indicates different $p$ value for each variable, such as age ( $p$-value $=0.445)$, nutritional status ( $p$-value $=0.802)$, years of working $(p$-value $=0.025)$, exercise habits $(p$-value $=0.268)$, and education level ( $p$-value $=0.076)$. There is a significant difference between occupational stress and years of working and Inadequate Preparation Scale is the source of occupational stress that has highest prevalence.

\section{PENDAHULUAN}

Stres kerja merupakan hazard psikososial yang berasal dari berbagai sumber seperti, organisasi kerja, desain kerja, kondisi kerja dan hubungan rekan kerja. Stres kerja akan muncul ketika pengetahuan dan kemampuan koping, atau biasa disebut penyelesaian masalah pada pekerja individu atau sekelompok pekerja, tidak sesuai dengan tuntutan pekerjaan yang ada dan harapan serta budaya organisasi perusahaan di tempat mereka bekerja. Hal ini akan menjadi risiko 
dalam kesehatan dan keselamatan kerja. ${ }^{1}$

Stres kerja merupakan salah satu permasalahan yang sering dialami di berbagai belahan dunia. Saat ini stres kerja sendiri telah menjadi isu global yang sangat berpengaruh pada seluruh profesi dan pekerja baik di negara maju maupun berkembang. ${ }^{2}$ The American Institute of Stress, sebuah organisasi yang menyediakan berbagai informasi tentang semua subjek yang terkait stres, mengungkapkan bahwa $61 \%$ masyarakat di beberapa negara bagian di Amerika mendapatkan sumber stres yang berasal dari pekerjaan. ${ }^{3}$ Data statistik Britania Raya tahun 2019 juga menunjukkan bahwa 602.000 pekerja di Britania Raya mengalami stres, depresi, dan kecemasan. ${ }^{4}$

Sektor-sektor pekerjaan yang dilaporkan sering mengalami stres kerja di antaranya yaitu, bidang kesehatan, pendidikan, pelayanan, keuangan, perdagangan ritel, transportasi dan konstruksi, serta sektor publik. $^{2}$ Perawat sebagai salah satu pekerja dari sektor kesehatan juga memiliki risiko untuk mengalami stres kerja. Data yang berasal dari Persatuan Perawat Nasional Indonesia atau PPNI dalam Febriani et $\mathrm{al}^{5}$ menyatakan bahwasannya $50,9 \%$ perawat Indonesia di tahun 2006 mengalami stres kerja.

Penelitian milik Starc $^{6}$ mengungkapkan bahwa terdapat perbedaan tingkat stres di antara perawat pria dan perawat wanita. Perbedaan tingkat stres antara perawat pria dan perawat wanita tersebut dipengaruhi oleh beberapa faktor yang menyebabkan perawat wanita menjadi lebih stres daripada perawat pria yaitu, hubungan di antara rekan kerja, kekerasan psikologis atau fisik di tempat kerja, dan faktor pasien.

Mayoritas perawat wanita di Indonesia yang merupakan wanita juga harus menjadi perhatian khusus. Perawat wanita merupakan pekerja yang umumnya memiliki peran ganda, yaitu sebagai perawat yang dituntut untuk selalu siap memberikan pelayanan terbaik dan mengurus keluarga di rumah. Tuntutan ini membuat perawat harus dapat menyeimbangkan tugas kerja sebagai perawat dan tuntutan sebagai anggota keluarga yang berpotensi untuk menciptakan pekerjaan konflik keluarga. Konflik keluarga tersebut dapat memperparah stres kerja di lingkungan kerja yang berdampak pada kinerja perawat wanita. Pekerjaan perawat wanita akan menjadi tidak nyaman dan terganggu dan memengaruhi kinerja perawat wanita. ${ }^{7}$ Kondisi ini mendasari peneliti untuk melakukan penelitian mengenai stres kerja terhadap perawat wanita di RS. X Palembang. Penelitian ini bertujuan untuk mengetahui angka stres kerja perawat berdasarkan sumber stres kerja pada perawat wanita di RS. X Palembang.

\section{BAHAN DAN CARA}

Penelitian ini merupakan jenis penelitian deskriptif dengan menggunakan pendekatan cross-sectional. Penelitian ini dilakukan dengan mengambil sampel perawat wanita di RS. X Palembang. Populasi dalam penelitian ini merupakan perawat wanita di RS.

X. Palembang. Sampel yang diambil dalam penelitian ini adalah sebanyak 54 orang perawat wanita di RS. X Palembang. Data yang diambil merupakan data primer yang diambil dengan instrumen kuisioner dengan metode wawancara.

Kuisioner yang digunakan merupakan kuisioner Expanded Nursing Stress Scale atau ENSS yang diterjemahkan ke dalam Bahasa Indonesia oleh Hastono $^{8}$ yang terdiri atas 9 subskala yaitu subskala kematian dan sekarat, subskala konflik dengan dokter, subskala tidak cukup persiapan, subskala permasalahan dengan teman kerja, subskala dengan supervisor/atasan, subskala ketidakjelasan pengobatan, subskala permasalahan dengan 
pasien, subskala beban kerja, dan subskala diskriminasi. Peneliti hanya menggunakan 8 subskala stres kerja yaitu, subskala kematian dan sekarat, subskala konflik dengan dokter, subskala tidak cukup persiapan, subskala permasalahan dengan teman kerja, subskala dengan supervisor/atasan, subskala ketidakjelasan pengobatan, subskala permasalahan dengan pasien, dan subskala beban kerja. Hal ini berdasarkan penelitian yang dilakukan oleh French et al. ${ }^{9}$ Penelitian tersebut mengemukakan bahwa nilai koefisien alpha dapat mengukur tingkat stres secara adekuat jika variabel diskriminasi dihilangkan.

Kuisioner ini dapat menggunakan dua cara penilaian yaitu skor total didapatkan dengan menjumlahkan seluruh skor pada semua butir, termasuk yang bernilai 0 . Semakin tinggi skor total, semakin tinggi stres yang dialami, Cara yang kedua yaitu dapat juga dengan menggunakan rerata nilai per subskala, semakin tinggi rerata nilai maka semakin tinggi stress yang dialami. ENSS tidak memiliki klasifikasi apakah tingkat stres kerja seseorang tergolong rendah, sedang, atau tinggi. ${ }^{10}$

Penelitian ini menggunakan cara penilaian dengan menggunakan nilai rerata subskala. Data yang didapatkan dari hasil wawancara dengan sampel tersebut kemudian diolah terlebih dahulu melalui beberapa tahap yaitu editing, coding, scoring, dan cleaning. Uji yang digunakan dalam penelitian ini merupakan uji Chi-Square.

\section{HASIL}

Karakteristik responden pada tabel 1 yang ada dalam penelitian ini menunjukkan bahwa responden didominasi oleh perawat wanita dengan usia 18-39 tahun yaitu sebanyak 33 orang $(61,1 \%)$, latar belakang pendidikan Diploma 3 sebanyak 39 orang $(72,2 \%)$, status gizi yang mencapai angkat obesitas 26 orang (48\%), masa kerja >15 tahun sebanyak 32 orang $(59,3 \%)$, dan melakukan kebiasaan olahraga satu kali seminggu sebanyak 23 orang $(42,6 \%)$.

Tabel 1. Karakteristik Responden

\begin{tabular}{ccc}
\hline Karakteristik & $\begin{array}{c}\text { Jumlah } \\
\text { N = 54 }\end{array}$ & $\%$ \\
\hline Usia & & \\
$18-39$ tahun & 33 & $61,1 \%$ \\
$\geq 40$ tahun & 21 & $38,9 \%$
\end{tabular}

Tingkat Pendidikan

$\begin{array}{ccc}\text { D3 } & 39 & 72,2 \% \\ \text { S1 } & 5 & 9.3 \% \\ \text { Ners } & 10 & 18,5 \%\end{array}$

\section{Status Gizi}

BB kurang dari normal $4 \quad 7,4 \%$

BB Normal $\quad 8 \quad 14,8 \%$

BB berlebih $\quad 16 \quad 29,6 \%$

Obesitas $26 \quad 48,1 \%$

\section{Masa Kerja}

$\begin{array}{lll}\leq 15 \text { tahun } & 22 & 40,7 \% \\ >15 \text { tahun } & 32 & 59,3 \%\end{array}$

\section{Kebiasaan Olahraga}

$\begin{array}{ccc}\text { Tidak pernah } & 21 & 38,9 \% \\ \text { 1 kali seminggu } & 23 & 42,6 \% \\ >1 \text { kali seminggu } & 10 & 18,5 \%\end{array}$

Tabel 2 menunjukkan distribusi stres kerja pada responden berdasarkan subskala dari ENSS. Hasil yang didapatkan yaitu untuk skor keseluruhan stres kerja didapatkan sebanyak $21(38,9 \%)$ orang dengan nilai lebih tinggi dari rerata nilai. Penghitungan skor juga dilakukan berdasarkan kedelapan subskala yaitu, Subskala Kematian dan Sekarat dengan responden yang mendapat nilai lebih tinggi dari rerata sebanyak 28 orang $(51,9 \%)$, Subskala Konflik dengan Dokter dengan responden yang mendapat nilai lebih tinggi dari rerata sebanyak 24 orang $(44,4 \%)$, Subskala Tidak Cukup Persiapan dengan responden yang mendapat nilai lebih tinggi dari rerata sebanyak 32 orang (59,3\%), 
Subskala Permasalahan dengan Teman Kerja dengan responden yang mendapat nilai lebih tinggi dari rerata sebanyak 23 orang $(42,6 \%)$, Subskala Permasalahan dengan Supervisor/Atasan dengan responden yang mendapat nilai lebih tinggi dari rerata sebanyak 22 orang (40,7\%), Subskala Ketidakjelasan Pengobatan dengan responden yang mendapat nilai lebih tinggi dari rerata sebanyak 22 orang $(40,7 \%)$, Subskala Permasalahan dengan Pasien dengan responden yang mendapat nilai lebih tinggi dari rerata sebanyak 29 orang $(53,7 \%)$, dan Subskala Beban Kerja dengan responden yang mendapat nilai lebih tinggi dari rerata sebanyak 24 orang $(44,4 \%)$.

Tabel 2. Distribusi Stres Kerja berdasarkan Subskala ENSS

\begin{tabular}{|c|c|c|}
\hline Subskala & $\begin{array}{l}\text { Skor }> \\
\text { Rerata } \\
N=54\end{array}$ & $\begin{array}{l}\text { Skor }< \\
\text { Rerata } \\
\mathbf{N}=\mathbf{5 4}\end{array}$ \\
\hline $\begin{array}{l}\text { Subskala Kematian } \\
\text { dan sekarat }\end{array}$ & 27 & 26 \\
\hline $\begin{array}{l}\text { Subskala Konflik } \\
\text { dengan dokter }\end{array}$ & 24 & 30 \\
\hline $\begin{array}{l}\text { Subskala Tidak Cukup } \\
\text { Persiapan }\end{array}$ & 32 & 22 \\
\hline $\begin{array}{l}\text { Subskala } \\
\text { Permasalahan dengan } \\
\text { Teman Kerja }\end{array}$ & 23 & 31 \\
\hline $\begin{array}{l}\text { Subskala } \\
\text { Permasalahan dengan } \\
\text { Supervisor/Atasan }\end{array}$ & 22 & 32 \\
\hline $\begin{array}{l}\text { Subskala } \\
\text { Ketidakjelasan } \\
\text { Pengobatan }\end{array}$ & 22 & 32 \\
\hline $\begin{array}{l}\text { Subskala } \\
\text { Permasalahan dengan } \\
\text { Pasien }\end{array}$ & 29 & 25 \\
\hline Subskala Beban Kerja & 24 & 30 \\
\hline
\end{tabular}

Sumber: Data Primer, 2020
Hasil berikutnya pada tabel 3 menunjukkan hubungan stres kerja dengan karakteristik responden dan ditemukan bahwa terdapat perbedaan yang bermakna antara stres kerja dengan masa kerja ( $p$-value $=0,025)$, dan tidak ditemukan perbedaan yang bermakna antara stres kerja dengan usia ( $p$ value $=0,445)$, status gizi ( $p$-value $=0,802)$, kebiasaan olahraga ( $p$-value $=0,268)$, dan tingkat pendidikan $(p$-value $=0,076)$.

Tabel 3. Hubungan Stres Kerja dengan Karakteristik Responden

\begin{tabular}{|c|c|c|}
\hline Karakteristik & $\begin{array}{c}\text { Skor Lebih } \\
\text { Tinggi dari } \\
\text { Rerata } \\
\text { N = 54 }\end{array}$ & $\begin{array}{c}\text { Skor } \\
\text { Lebih } \\
\text { Rendah } \\
\text { dari } \\
\text { Rerata } \\
\text { N = 54 }\end{array}$ \\
\hline Usia & & \\
\hline 18-39 tahun & 10 & 11 \\
\hline $\begin{array}{c}\geq 40 \text { tahun } \\
\text { Tingkat }\end{array}$ & 11 & 22 \\
\hline Pendidikan & 12 & 27 \\
\hline D3 & 2 & 3 \\
\hline S1 & 7 & 3 \\
\hline Ners & & \\
\hline Status Gizi & 2 & 2 \\
\hline $\begin{array}{c}\text { BB kurang dari } \\
\text { normal }\end{array}$ & 2 & 6 \\
\hline BB Normal & 6 & 10 \\
\hline $\begin{array}{c}\text { BB berlebih } \\
\text { Obesitas }\end{array}$ & 11 & 15 \\
\hline Masa Kerja & 13 & 9 \\
\hline $\begin{array}{l}\leq 15 \text { tahun } \\
>15 \text { tahun }\end{array}$ & 8 & 24 \\
\hline Kebiasaan & 11 & 10 \\
\hline Olahraga & 7 & 16 \\
\hline $\begin{array}{l}\text { Tidak pernah } \\
1 \text { kali } \\
\text { seminggu } \\
>1 \text { kali } \\
\text { seminggu }\end{array}$ & 3 & 7 \\
\hline
\end{tabular}




\section{PEMBAHASAN}

Sumber stres kerja dengan angka tertinggi yang dialami oleh perawat wanita di RS. X Palembang berdasarkan 8 subskala ENSS terdapat pada Subskala Tidak Cukup Persiapan, diikuti dengan Subskala Permasalahan dengan Pasien, Subskala Kematian dan Sekarat, Subskala Konflik dengan Dokter, Subskala Beban Kerja, Subskala Permasalahan dengan Teman, Permasalahan dengan Supervisor/Atasan, dan Subskala Ketidakjelasan Pengobatan. Stres kerja yang diakibatkan tidak cukupnya persiapan ini biasanya dikarenakan tuntutan kebutuhan informasi pasien terhadap informasi kesehatan maupun pengobatannya sendiri. Mayoritas pasien di RS.X cenderung lebih nyaman untuk berinteraksi dengan perawat dibandingkan dengan dokter. Alasannya tak lain adalah karena dokter memiliki kesibukan yang tinggi dimana mereka harus siap dipanggil ke ruangan instalasi manapun yang membutuhkan mereka, hal ini mengakibatkan terbatasnya waktu pasien untuk berinteraksi secara langsung dengan dokter, padahal dokter memiliki tanggungjawab unruk memberikan informasi kepada pasien secara langsung terkait pengobatannya.

Komunikasi antara pasien dan dokter yang kurang efektif ini bukannya tidak memiliki alasan. Bakić-Mirić NM dan Bakić NM menyatakan bahwasannya terdapat beberapa halangan yang dijumpai saat membangun komunikasi yang efektif antara dokter dan pasiennya, seperti, pasien yang merasa cemas secara berlebihan, pasien yang tidak mampu menerima penjelasan dokter mengenai kondisinya, dokter yang merasa terbebani atas pekerjaannya, pasien yang tidak menyetujui suatu tindakan medis yang akan dilakukan oleh dokter, serta pemikiran pasien yang seringkali tidak realistis. ${ }^{11}$ Kurang efektifnya komunikasi antara pasien dan dokter menyebabkan pasien lebih memilih untuk bertanya kepada perawat, di sisi lain perawat tidak memiliki kewenangan yang banyak untuk memberikan informasi terkait pengobatan pasien seperti yang diberikan oleh dokter. Hal ini menimbulkan beban tersendiri bagi perawat, selain itu pasien cenderung senang berkeluh kesah dengan perawat khususnya perawat wanita karena perawat wanita memiliki sifat empati yang lebih tinggi dibandingkan perawat pria terkait pengobatan yang sedang dijalaninya.

Karakteristik responden dalam penelitian ini terdiri atas karakteristik responden yang umumnya sering terdapat pada perawat wanita, yaitu usia, tingkat pendidikan, status gizi, masa kerja, dan kebiasaan olahraga. Penelitian ini membuktikan bahwa perawat wanita dengan usia 18-39 tahun, ditemukan lebih banyak mendapat nilai di bawah nilai rerata, sedangkan pada usia $\geq 40$ tahun ditemukan lebih banyak perawat wanita yang memiliki nilai diatas nilai rerata. Kelompok umur dalam penelitian ini dengan penelitian Jusnimar dalam Hasanah $^{12}$ yang mengungkapkan bahwasannya, sebagian besar perawat memiliki konflik dalam jumlah kelompok yang rendah pada usia 41-60. Hal ini disebabkan oleh individu memasuki fase dewasa tengah yaitu usia 41- 60 yang secara perkembangan psikologis akan lebih matang serta bijaksana, lebih kreatif serta produktif, dapat menjadi pendidik, pengawas bagi generasi selanjutnya. Bertambahnya usia seorang individu dapat meningkatkan kemampuan pengambilan keputusan, semakin bijaksana dan lebih siap menghadapi stres.

Perawat wanita dengan tingkat pendidikan lebih tinggi umumnya memiliki nilai stres di atas rerata yang lebih tinggi dibandingkan dengan yang memiliki nilai lebih rendah dari rerata dikarenakan memiliki tanggungjawab yang lebih tinggi karena dianggap lebih berkompeten. Penelitian yang dilakukan di enam belas negara di Eropa milik Lunau et $\mathrm{al}^{13}$ memberikan temuan utama yang 
menunjukkan hubungan yang konsisten antara pendidikan yang rendah dan tingkat stres kerja yang lebih tinggi di semua negara. Kekuatan asosiasi tersebut bervariasi di berbagai negara. Golubic et $\mathrm{al}^{14}$ juga menyatakan bahwa terdapat perbedaan antara perawat dengan kualifikasi sekolah menengah dengan perawat dengan gelar sarjana. Perawat dengan kualifikasi sekolah menengah menganggap hazard di tempat kerja dan shift kerja secara statistik jauh lebih membuat stress.

Responden didominasi dengan status gizi berat badan berlebih dan obesitas, hal ini dikarenakan responden cenderung susah untuk menjangkau makanan selingan yang sehat di sela-sela padatnya jam kerja, sehingga biasanya mereka hanya menjangkau jajanan yang mengandung minyak dan kolesterol tinggi. Purwanti et $\mathrm{al}^{15}$ menyatakan bahwa semakin tinggi BMI yang ditunjukkan dengan status obesitas, maka semakin tinggi tingkat stres kerja yang dialami oleh responden tersebut. Penelitian milik Shinde ${ }^{16}$ menyatakan bahwa sebanyak 262 peserta menemukan korelasi lemah indeks massa tubuh dengan perilaku makan dan stres kerja.

Responden dengan masa kerja $\leq 15$ tahun lebih banyak mendapat skori stres di atas rerata, sedangkan responden dengan masa kerja >15 tahun lebih banyak mendapat skor stress di bawah nilai rerata. Responden dengan masa kerja lebih lama cenderung sudah beradaptasi dengan baik dengan lingkungan kerja yang ada, sehingga mereka sudah terbiasa dengan berbagai macam tekanan dan memiliki metode koping yang baik saat menjalani pekerjaan mereka. Hasil analisis regresi berganda dari penelitian milik Dewi et $\mathrm{al}^{17}$, menunjukkan bahwasannya masa kerja dan stres kerja memiliki hubungan yang signifikan dan memiliki faktor yang paling berperan dalam menentukan perasaan kelelahan kerja pada perawat. Penelitian milik
Fitri $^{18}$ menyatakan bahwa ada hubungan antara masa kerja dengan stres kerja.

Responden yang memiliki kebiasaan olahraga juga cenderung memiliki skor stres yang rendah, hal ini dikarenakan saat olahraga mereka merasa seperti telah melepaskan segala penat yang ada di dalam diri mereka, sehingga stres akibat bekerja pun berkurang. Hal ini selaras dengan penelitian Andalasri et al $^{19}$ didapatkan bahwa kebiasaan olahraga terhadap tingkat stress mempunyai hubungan yang tinggi, dan pengaruh yang signifikan.

\section{KESIMPULAN DAN SARAN}

Subskala Tidak Cukup Persiapan merupakan sumber stres kerja dengan angka tertinggi yang dialami oleh perawat wanita di RS. X Palembang berdasarkan 8 subskala ENSS. Terdapat perbedaan yang bermakna antara stres kerja dengan masa kerja, dan tidak ditemukan perbedaan yang bermakna antara stres kerja dengan usia, status gizi, kebiasaan olahraga, dan tingkat pendidikan.

Peneliti menyarankan agar pihak RS.X berkoordinasi dengan komite keperawatan untuk mengadakan diskusi terbuka dalam jangka waktu tertentu semisal sebulan sekali dengan kepala instalasi mengenai keluhan yang sering dialami perawat khususnya perawat wanita saat bekerja di lapangan. Hasil ini diskusi ini diharapkan dapat dikomunikasikan dengan pimpinan rumah sakit untuk ditindaklanjuti, sehingga angka stres kerja dapat dikurangi.

\section{UCAPAN TERIMA KASIH}

Terima kasih peneliti ucapkan kepada Direktur RS X Palembang yang telah mengizinkan peneliti untuk melakukan penelitian di RS X dan semua pihak yang telah membantu proses penyelesaian penelitian ini penulis ucapkan terimakasih semoga penelitian ini dapat bermanfaat bagi kita semua. 


\section{DAFTAR PUSTAKA}

1. International Labour Organization. Psychosocial risks, stress and violence. Int J Labour Res. 2017;8(1-2).

2. International Labour Organization. Workplace Stress: A Collective Challenge.; 2016.

3. The American Institute of Stress. Stress Research. Stress Research.

4. HSE. Work-related stress, anxiety or depression statistics in Great Britain, 2019. Апnu Stat. Published online 2019:1-9.

5. Febriani S, Satrianegara F, Ibrahi IA. Gambaran Stres Kerja pada Perawat di Ruang Rawat Inap Bagian Perawatan Jiwa RSKD Provinsi Sulawesi Selatan. Published online 2017.

6. Starc J. Stress Factors among Nurses at the Primary and Secondary Level of Public Sector Health Care: The Case of Slovenia. Open Access Maced J Med Sci. 2018;6(2):416-422.

doi:10.3889/oamjms.2018.100

7. Kikuchi Y, Nakaya M, Ikeda M, Okuzumi S, Takeda M, Nishi M. Relationship between job stress, temperament and depressive symptoms in female nurses. Int $\mathrm{J}$ Occup Med Environ Health. 2014;27(3):426-434. doi:10.2478/s13382-014-0270-z

8. Harsono H. Uji Validitas dan Reliabilitas Expanded Nursing Stress Scale (ENSS) Versi Bahasa Indonesia sebagai Instrumen Penilaian Stres Kerja pada Perawat di Indonesia. Published online 2017.

9. French SE, Lenton R, Walters V, Eyles J. An empirical evaluation of an expanded nursing stress scale. J Nurs Meas. 2000;8(2):161-178. doi:10.1891/1061-3749.8.2.161

10. Herqutanto, Harsono H, Damayanti M, Setiawati EP. Stres Kerja pada Perawat di Rumah Sakit dan Fasilitas Pelayanan
Kesehatan Primer. eJournal Kedokt Indones.2017;5(1):12-17. doi:10.23886/ejki.5.7444.12-7

11. Menawati T, Kurniawan H. Pentingnya Komunikasi Dalam Pelayanan Kesehatan Primer. $J$ Kedokt Syiah Kuala. 2015;15(2):120-124.

12. Hasanah L, Rahayuwati L, Yudianto K. Sumber Stres Kerja Perawat Di Rumah Sakit. J Persat Perawat Nas Indones. 2020;3(3):111. doi:10.32419/jppni.v3i3.162

13. Lunau T, Siegrist J, Dragano N, Wahrendorf $\mathrm{M}$. The association between education and work stress: Does the policy context matter? PLoS One. 2015;10(3):1-17.

doi:10.1371/journal.pone.0121573

14. Golubic R, Milosevic M, Knezevic B, Mustajbegovic J. Work-related stress, education and work ability among hospital nurses. $J$ Adv Nurs. 2009;65(10):2056-2066. doi:10.1111/j.1365-2648.2009.05057.x

15. Purwanti M, Putri EA, Ilmiawan IM, Wilson, Rozalina. Hubungan Tingkat Stres dengan Indeks Massa Tubuh Mahasiswa PSPD FK UNTAN. 2017;3(2):1-10.

16. Shinde VV. Relationship of body mass index to job stress and eating behaviour in health care professionals-an observational study. Obes Med. 2019;14(October 2018): 100070 doi:10.1016/j.obmed.2018.12.002

17. Dewi AC, Surono A, Sutomo AH. Work stress, age, and years of service with feeling of work fatigue among nurses at Grhasia hospital Yogyakarta. Ber Kedokt Masy.2016;32(2):53. doi:10.22146/bkm.8569

18. Fitri AM. Analisis Faktor-faktor yang Berhubungan dengan Kejadian Stres Kerja pada Karyawan Bank (Studi pada Karyawan Bank BMT). J Kesehat Masy. 
2013;2(1).

19. Andalasari R, BL AB. Kebiasaan

Olahraga Berpengaruh Terhadap Tingkat

Stress Mahasiswa Poltekkes Kemenkes

Jakarta III. J Ilmu dan Teknol Kesehat.

2018;5(2):179-191. 